\title{
Early sepsis biomarkers and their relation to mortality
}

\author{
Andreea Cioara $^{1}$, Madalina Valeanu ${ }^{1}$, Nicolae Todor $^{2}$, Victor Cristea $^{1}$, Mihaela Lupse $^{1}$ \\ 1 "Iuliu Hațieganu” University of Medicine and Pharmacy, Cluj-Napoca, Romania \\ 2 "Prof. Dr. Ion Chiricuță" Institute of Oncology, Cluj-Napoca, Romania
}

To the Editor,

Mortality in septic patients is predicted based on the initial physiological impairments grouped in the functional severity scores APACHE II and SOFA, but recently, the predictive ability of early serum concentrations of cytokines has been investigated in specific ICU (Intensive Care Unit) patient categories with systemic inflammatory syndromes [1]. However, the prognostic values of cytokines and their correlation with mortality are not fully established.

The aim of this study was to investigate the prognostic values of interleukin-6 (IL-6), interleukin-8 (IL8) and interleukin 1-receptor antagonist (IL1-Ra), as well as procalcitonine (PCT) and serum lactate in septic patients.

Fourteen adult patients with sepsis and septic shock were included in this preliminary prospective observational study. The patients were admitted to the ICU of the Teaching Hospital of Infectious Diseases, ClujNapoca, between $1^{\text {st }}$ of May and $31^{\text {st }}$ of July 2013. The investigation was accepted by the Ethical Committee of the Cluj-Napoca University of Medicine and Pharmacy and informed consent according to the Helsinki Declaration was obtained from each patient. Sepsis and septic shock were defined according to current recommendations [2]. We excluded patients receiving immunosuppressant drugs, patients with malignancy or human immunodeficiency virus infections.

Serum levels of PCT were measured with VIDAS (BioMerieux) and the serum level of lactate with Cobas C311 (Roche Diagnostics) in all samples, immediately after taking. We also measured the serum level of proinflammatory cytokines (IL-6, IL-8) and anti-inflammatory cytokines (IL1-Ra) using sandwich ELISA (ELISA Sanquin, R\&D Systems). Serum samples were collected at the time of admission and 24 hours after admission in our intensive care unit. For cytokines, we stored the serum at $-80^{\circ} \mathrm{C}$ and we measured all samples in the same day.

Adress for correspondence:

Dr. Andreea Cioara

23, Iuliu Moldovan Street

Cluj-Napoca, Romania

E-mail: paula_cioara@yahoo.com
We performed the Chi-square test to compare nonparametric data and the receiver-operating characteristics curves (ROC), with the level of significance set at $p<0.05$, to analyze the accuracy of mortality prediction by estimating the area under the curve.

From 14 patients aged 44-93, the majority were females (9 patients), and 9 patients died (mortality was $64.28 \%$ ). Seven patients had septic shock and 7 patients had sepsis. Eight patients had respiratory sepsis, followed by sepsis derived from complicated skin and soft tissue infection in two patients, 1 patient had an intra-abdominal infection, and 3 patients had sepsis of unknown origin.

Based on the ROC curve analysis, the serum levels of the studied biomarkers at admission and at $24 \mathrm{~h}$ after admission were correlated with mortality (Fig. 1).

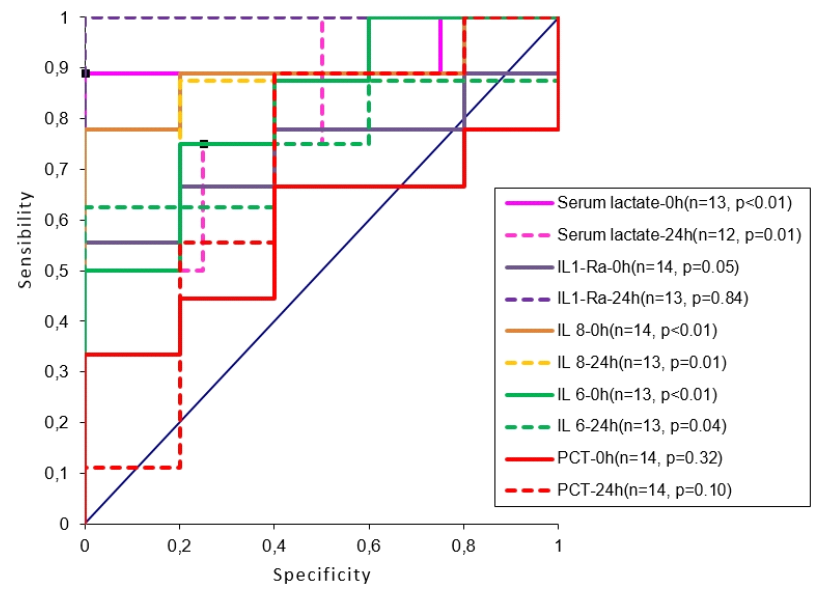

Fig. 1. ROC curve analysis for the correlation of PCT, lactate, IL-6, IL-8, and IL1-Ra with sepsis mortality

PCT and IL1-Ra were not correlated with mortality ( $\mathrm{p}>0.05)$. Lactate levels $(2.67 \pm 2.98 \mathrm{mg} / \mathrm{dL}$ at admission, and $1.95 \pm 2.12 \mathrm{mg} / \mathrm{dL}$ at $24 \mathrm{~h}$ ) were correlated with mortality, with cut-off values of 1.9 $\mathrm{mg} / \mathrm{dL}$ at admission $(\mathrm{p}<0.01)$, and $1.7 \mathrm{mg} / \mathrm{dL}$ at 24 hours $(\mathrm{p}=0.01)$, discriminating between survivors and non-survivors. IL-6 levels $(748.44 \pm 1461.01 \mathrm{pg} / \mathrm{mL}$ at admission, and $190.20 \pm 392.62 \mathrm{pg} / \mathrm{mL}$ at $24 \mathrm{~h}$ ) were 
correlated with mortality, with cut-off values of 36.3 $\mathrm{pg} / \mathrm{mL}(\mathrm{p}<0.01)$ at admission, and $68.7 \mathrm{pg} / \mathrm{mL}(\mathrm{p}=$ $0.04)$ at 24 hours. IL-8 $(692.61 \pm 1410.21 \mathrm{pg} / \mathrm{mL}$ at admission, and $207.97 \pm 335.81 \mathrm{pg} / \mathrm{mL}$ after 24 hours) discriminated between non-survivors and survivors, with cut-off values of $81.7 \mathrm{pg} / \mathrm{mL}(\mathrm{p}<0.01)$, and 47.3 $\mathrm{pg} / \mathrm{mL}$ respectively $(\mathrm{p}=0.01)$.

The diagnostic role of PCT in sepsis is already established [3], and PCT serum levels are correlated to sepsis severity [4]. In our study we did not find a significant correlation between serum levels of PCT and sepsis outcome in terms of mortality, probably due to the small number of patients included.

Hyperlactatemia due to tissue hypoxia and anaerobic glycolysis is common in sepsis and lactate is an independent predictor of mortality in sepsis. In our study, serum lactate at admission and at 24 hours after admission were associated with mortality, when specific cut-offs were chosen (approximately $1.7-1.9 \mathrm{mg}$ / $\mathrm{dL}$ ). These values we identified by performing ROC curve analysis, are close to the previously described ones [5].

Studies suggest that the main role of IL-6 in sepsis is prognostic, not diagnostic. Serum levels of IL-6 in sepsis are elevated early, identifying patients at a risk of developing severe sepsis, and are associated with increased mortality [6]. Andaluz-Ojeda et al. concluded that in patients with sepsis, serum concentration of IL6 are elevated in non-survivors and are associated with early mortality on day 3 and later on in day 28 [7]. Our data highlighted that serum levels of IL-6 at admission and after 24 hours were significantly correlated with mortality, with cut-off values of $36.3 \mathrm{pg} / \mathrm{mL}$ at admittance and $68.7 \mathrm{pg} / \mathrm{mL}$ at 24 hours. These findings suggest that early serum levels of IL- 6 might be a predictor for sepsis outcome.

IL-8 is a proinflammatory cytokine with important roles in inflammation and host defense. IL- 8 has been found to be predictive for sepsis-related mortality. It has been proved that in septic patients serum levels of IL-8 are elevated in non-survivors and are associated with early mortality and with 28 day mortality $[6,7]$. We found that serum levels of IL- 8 discriminated early between non-survivors and survivors, with cut-off values of $81.7 \mathrm{pg} / \mathrm{mL}$ at admittance and $47.3 \mathrm{pg} / \mathrm{mL}$ after 24 hours.

IL-1-Ra is an anti-inflammatory cytokine. Previous studies suggested that IL1-Ra is one of the best predictors of mortality in septic shock, non-survivors having significantly higher values of IL1-Ra [8]. In our study, we did not find any significant correlation of serum levels of IL1-Ra and mortality.

The limits of our study consist of the limited number of patients. In addition, the ranges for the cytokine concentrations displayed a wide distribution. However, our data suggests that mortality is correlated with serum levels of lactate, as an indicator of tissue hypoxia and the severity of organ dysfunction, and with IL-6 and IL-8 serum concentrations, as markers of the proinflammatory state which appears due to immune dysregulations in sepsis. PCT and IL1-Ra do not seem to discriminate early between survivors and non-survivors, a conclusion that needs confirmation by the performance of larger studies.

In conclusion, lactate concentrations, IL-6 and IL8 values, but not PCT and IL1-Ra, discriminate early between survivor and non-survivor septic patients, and might be used as prognostic parameters in the future.

\section{Conflict of interest}

Nothing to declare

\section{References}

1. Trancă S, Oever JT, Ciuce C, Netea M, Slavcovici A, Petrişor C, et al. sTREM-1, sIL-2R $\alpha$, and IL-6, but not sCD163, might predict sepsis in polytrauma patients: a prospective cohort study. Eur J Trauma Emerg Surg 2016 May 12; [Epub ahead of print]. DOI: $10.1007 / \mathrm{s} 00068-016-0678-1$

2. Singer M, Deutschman CS, Seymour CW, Shankar-Hari M, Annane D, Bauer M, et al. The Third International Consensus Definitions for Sepsis and Septic Shock (Sepsis-3). JAMA 2016; 315: 801-810. DOI: 10.1001/jama.2016.0287

3. Reinhart K, Brunkhorst FM, Bone HG, Bardutzky J, Dempfle $\mathrm{CE}$, Forst $\mathrm{H}$, et al. Prevention, diagnosis, therapy and follow-up care of sepsis: 1 st revision of $\mathrm{S}-2 \mathrm{k}$ guidelines of the German Sepsis Society (Deutsche Sepsis-Gesellschaft e.V. (DSG)) and the German Interdisciplinary Association of Intensive Care and Emergency Medicine (Deutsche Interdisziplinäre Vereinigung für Intensiv- und Notfallmedizin (DIVI)). Ger Med Sci 2010; 8: Doc14. DOI: 10.3205/000103

4. Dellinger RP, Levy MM, Rhodes A, Annane D, Gerlach H, Opal $\mathrm{SM}$, et al. Surviving Sepsis Campaign: international guidelines for management of severe sepsis and septic shock, 2012. Crit Care Med 2013; 41: 580-637. DOI: 10.1097/CCM.0b013e $31827 \mathrm{e} 83 \mathrm{af}$

5. Schollin-Borg M, Nordin P, Zetterström H, Johansson J. Blood Lactate Is a Useful Indicator for the Medical Emergency Team. Crit Care Res Pract 2016; 2016: 5765202. DOI: 10.1155/2016/ 5765202

6. Gentile LF, Cuenca AG, Vanzant EL, Efron PA, McKinley B, Moore $\mathrm{F}$, et al. Is there value in plasma cytokine measurements in patients with severe trauma and sepsis? Methods 2013; 61: 3-9. DOI: 10.1016/j.ymeth.2013.04.024

7. Andaluz-Ojeda D, Bobillo F, Iglesias V, Almansa R, Rico L, Gandía F, et al. A combined score of pro- and anti-inflammatory interleukins improves mortality prediction in severe sepsis. Cytokine 2012; 57: 332-336. DOI: 10.1016/j.cyto.2011.12.002

8. Opal SM, DePalo VA. Anti-inflammatory cytokines. Chest 2000; 117:1162-1172

Rom J Anaesth Int Care 2016; 23: 159-160 